\title{
Title:
}

\section{Colonic vasculitis in a woman with end-stage kidney disease and HIV infection}

\section{Authors:}

Juan Diego Castro Limo, Francisco Javier Navajas León, Ángel Romo Navarro

DOI: $10.17235 /$ reed.2021.8363/2021

Link: PubMed (Epub ahead of print)

Please cite this article as:

Castro Limo Juan Diego, Navajas León Francisco Javier, Romo Navarro Ángel. Colonic vasculitis in a woman with end-stage kidney disease and HIV infection. Rev Esp Enferm Dig 2021. doi: 10.17235/reed.2021.8363/2021.

This is a PDF file of an unedited manuscript that has been accepted for publication. As a service to our customers we are providing this early version of the manuscript. The manuscript will undergo copyediting, typesetting, and review of the resulting proof before it is published in its final form. Please note that during the production process errors may be discovered which could affect the content, and all legal disclaimers that apply to the journal pertain. 


\section{Colonic vasculitis in a woman with end-stage kidney disease and HIV infection}

Juan Diego Castro Limo ${ }^{1}$, Javier Francisco Navajas León ${ }^{1}$, Ángel Romo Navarro²

Departments of ${ }^{1}$ Gastroenterology and ${ }^{2}$ Pathology. Complejo Hospitalario Universitario de Toledo

\section{Correspondence author:}

Juan Diego Castro Limo

Complejo Hospitalario Universitario de Toledo, Spain

Email: jd.castrolimo25@gmail.com

Keywords: Vasculitis. Colon.

Dear Editor,

We present the case of a 57-years old woman with bloody diarrhea, fever, and abdominal pain. Her medical history included HIV infection with undetectable viral load and end-stage kidney disease secondary to HIV on dialysis. At admission, she had a painful abdomen, no skin lesions and blood stools in rectal examination. Laboratory findings include a white blood cells count of $12,900 \times 103$ cells/ $\mu \mathrm{L}, \mathrm{CD} 4$ counts were 243 cells $/ \mu \mathrm{L}$ and C-reactive protein of $24.5 \mathrm{mg} / \mathrm{dl}$. Serologies, cytomegalovirus and PCR Sars-Cov2 were negative. Serum anti-neutrophil cytoplasmic antibody (ANCA, perinuclear pattern, 1/2560) with myeloperoxidase (MPO) specificity. Treatment with piperacillin-tazobactam and metronidazole was started, without clinical response. Colonoscopy identified deep oval and starry ulcers with well-defined borders throughout the colon (Fig. 1), and histology reveals focal images of parietal fibrinoid necrosis in a small-medium size vessel, suggestive of necrotizing vasculitis (Fig. C). The patient began treatment with intravenous methylprednisolone bolus (500 $\mathrm{mg}$ for 3 
days) and then tapering dose with symptoms resolution after five days. ANCA vasculitis (MPO) affects small and medium vessels, chin in an atypical presentation can affect the gastrointestinal tract. Areas of focal necrosis and ulcerations in colonoscopies were highly suggestive in taking biopsies.

\section{Discussion}

Gastrointestinal involvement of ANCA-associated vasculitis limited to the colon is a rather uncommon scenario (1). Colonoscopy show the multiple shallow ulcers with or without perforation. Colon biopsies may contribute to stablishing a specific diagnosis. Moreover, GI involvement in systemic necrotizing vasculitides has been associate with high mortality. There are few reports of colonic vasculitis without compromised other organs $(2,3)$.

\section{References}

1) Pagnoux C, Mahr A, Cohen P, et al. Presentation and outcome of gastrointestinal involvement in systemic necrotizing vasculitides: analysis of 62 patients with polyarteritis nodosa, microscopic polyangiitis, Wegener granulomatosis, Churg-Strauss syndrome, or rheumatoid arthritis-associated vasculitis. Medicine (Baltimore). 2005 Mar;84(2):115-128. Doi: 10.1097/01.md.0000158825.87055.0b. PMID: 15758841.

2) Silva J, Silva A, Furtado A, et al. Colon-Limited Leukocytoclastic Vasculitis. Am J Gastroenterol (2018) 113:1114. Doi: 10.1038/s41395-018-0081-0

3) Yoshikawa A, Yoshida S, Takeuchi T, et al. Gastrointestinal involvement at the onset of granulomatosis with polyangiitis: A case report. Mod Rheumatol. 2017 Jan;27(1):162-164. Doi: 10.3109/14397595.2014.954742. 

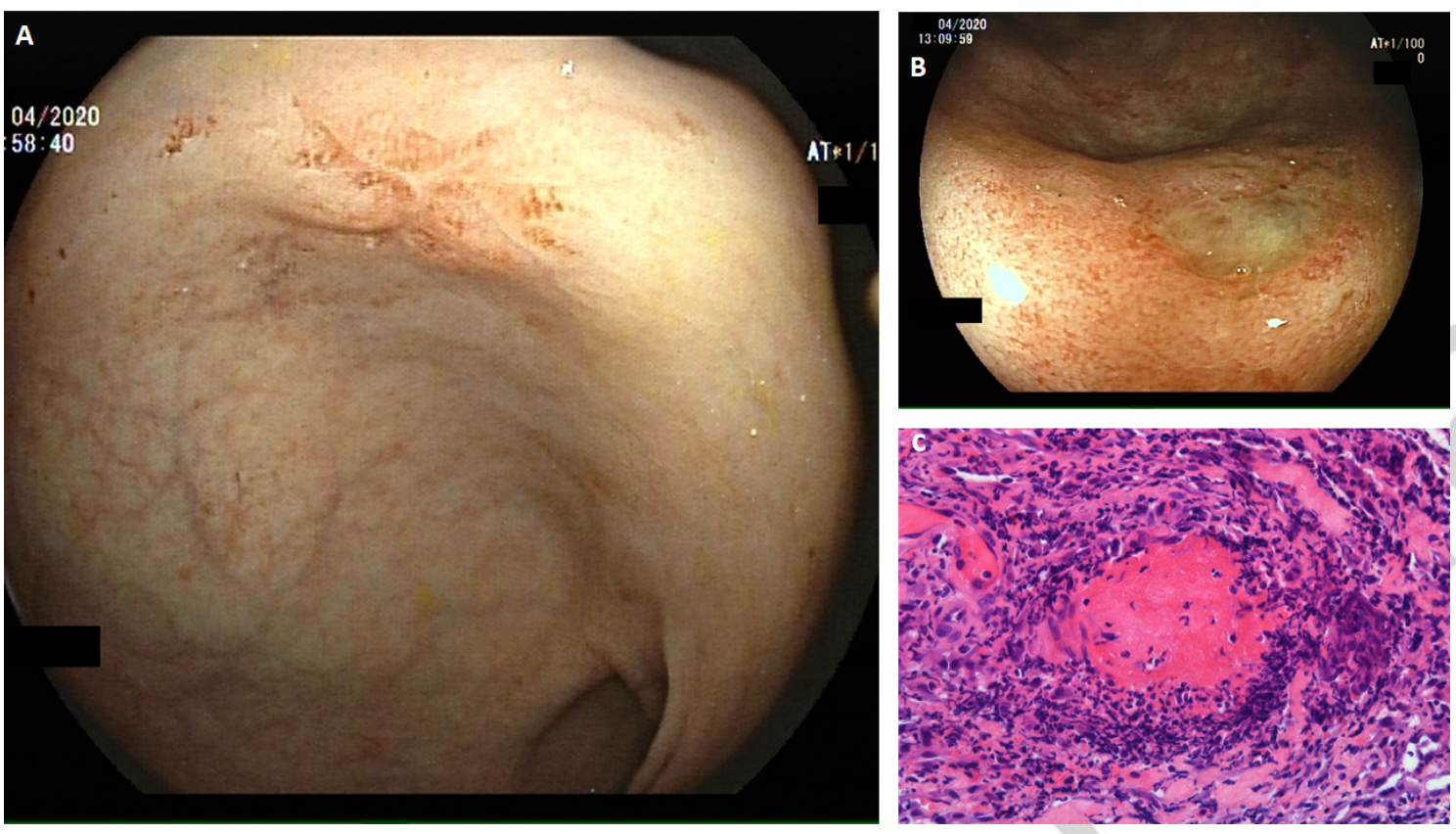

Figure 1. A and B) Deep oval and starry ulcers with well-defined borders in sigmoid and transverse colon biopsy during colonoscopy. C) Hematoxylin and eosin stain (100x and 400x). Colorectal mucosa with focal images of parietal fibrinoid necrosis in a smallmedium size vessel, suggestive of necrotizing vasculitis. Immunohistochemical stains showed a CD4/ CD8 lymphocyte ratio of 20/ 80, no granulomas (CD68-), microorganisms, HHV8, CMV or EBV were observed. 